\title{
Case Report \\ Successful Use of Pulmonary Vasodilators in Acute Chest Syndrome Complicated by Persistent Right Ventricular Failure
}

\author{
Jacqueline T. DesJardin $\mathbb{D D}^{1}$ and Lucas S. Zier $\mathbb{D}^{1,2}$ \\ ${ }^{1}$ Department of Internal Medicine, University of California San Francisco, San Francisco, CA, USA \\ ${ }^{2}$ Division of Cardiology, Zuckerberg San Francisco General Hospital and Trauma Center, San Francisco, CA, USA \\ Correspondence should be addressed to Lucas S. Zier; lucas.zier@ucsf.edu
}

Received 18 December 2018; Revised 25 February 2019; Accepted 1 April 2019; Published 18 April 2019

Academic Editor: Aiden Abidov

Copyright ( 2019 Jacqueline T. DesJardin and Lucas S. Zier. This is an open access article distributed under the Creative Commons Attribution License, which permits unrestricted use, distribution, and reproduction in any medium, provided the original work is properly cited.

\begin{abstract}
Pulmonary hypertension (PH) is a known consequence of sickle cell disease (SCD) and is associated with increased mortality and more frequent episodes of acute chest syndrome (ACS). Pulmonary pressures are known to increase during ACS, and right ventricular (RV) failure has been described as a significant cause of mortality in this condition. Management of ACS includes exchange transfusion, pain control, and prevention of hypovolemia and hypoxemia. However, in patients with a history of precapillary PH in whom ACS is complicated by persistent RV failure and cardiogenic shock, RV afterload reduction with pulmonary vasodilators may be an effective treatment strategy. Here, we present a case of a young man with SCD-associated PH and ACS who was successfully managed with inhaled and oral pulmonary vasodilators in the setting of persistent elevations in pulmonary vascular resistance leading to acute RV failure and cardiogenic shock.
\end{abstract}

\section{Introduction}

Pulmonary hypertension (PH) occurs in $10 \%$ of patients with sickle cell disease (SCD) and can be either pre- or postcapillary [1]. Due to anemia and reduced blood viscosity in SCD, even mild elevations in pulmonary vascular resistance (PVR) are indicative of precapillary physiology [2]. Precapillary SCD-associated PH is thought to be caused by reduced bioavailability of nitric oxide during hemolysis, chronic thromboembolism, and chronic hypoxia [3]. Six-year mortality in SCD-associated $\mathrm{PH}$ is $37 \%$, and those with a higher transpulmonary gradient and PVR have worse outcomes $[4,5]$. There may be a relationship between $\mathrm{PH}$ and risk of acute chest syndrome (ACS) given elevated pulmonary artery pressures (PAPs) have been associated with more frequent episodes of ACS [6].

The pathophysiology of ACS is complex and poorly understood; however, fundamentally ACS is due to vasoocclusion and/or vasoconstriction of the pulmonary microvasculature. PAPs increase during vasoocclusive pain crises and ACS, leading to increased RV afterload and the potential for RV failure $[7,8]$. In a study of 70 patients admitted to the intensive care unit with ACS, acute RV failure occurred in 11 patients (16\%) and was associated with a $40 \%$ mortality due to cardiogenic shock and multiple organ failure [8]. RV failure in ACS is often due to acute pressure overload in patients with baseline PH and RV dysfunction [9]. However, treatment of persistent RV failure in ACS is not well understood, particularly when PVR remains elevated after reversible causes of ACS have been addressed. Pulmonary vasodilators have not been formally studied in this setting, although they may have a role given our current physiologic understanding of ACS and RV failure.

Here, we present the case of a man with SCD complicated by $\mathrm{PH}$ who developed persistent RV failure and cardiogenic shock after an episode of ACS and was successfully managed with pulmonary vasodilators.

\section{Case Presentation}

A 38-year-old man with homozygous SCD presented to the emergency department with a sickle cell vasoocclusive pain crisis. On presentation, he reported one day of worsening midsternal chest pain and lower back pain. His initial workup 
was notable for normal vital signs, hemoglobin of 10.7 g/dL (baseline: $12.0 \mathrm{~g} / \mathrm{dL}$ ), absolute reticulocyte count of $374 \mathrm{k} / \mu \mathrm{L}$, creatinine of $1.16 \mathrm{mg} / \mathrm{dL}$, lactic acid of 1.5 $\mathrm{mmol} / \mathrm{L}$, undetectable troponin, and initial chest radiograph with clear lungs.

On further chart review, he had a history of remote pulmonary embolism and was on life-long warfarin therapy and a history of precapillary PH. Echocardiogram twentytwo months prior to admission showed a moderately enlarged RV with mildly reduced function and estimated pulmonary artery systolic pressure (ePASP) of $60 \mathrm{mmHg}$ (Figure 1(a)). Right heart catheterization (RHC) nineteen months prior to admission showed mild precapillary $\mathrm{PH}$ (Table 1). Pulmonary function testing showed forced expiratory volume in one second (FEV1) $72 \%$ predicted, forced vital capacity (FVC) $83 \%$ predicted, FEV1/FVC $71 \%$ predicted, and corrected diffusion capacity $45 \%$ predicted. A sleep study showed nocturnal desaturations and an apnea hypopnea index of 9.5, and he was placed on continuous positive airway pressure with supplemental oxygen at night. His $\mathrm{PH}$ was felt to be multifactorial given his history of SCD, mild obstructive sleep apnea and nocturnal hypoxia, and prior pulmonary embolism.

Following admission, he was started on intravenous fluids and opiates. On hospital day two, his oxygen saturation dropped to $83 \%$ and blood pressure to $76 / 55 \mathrm{mmHg}$. Arterial blood gas on $6 \mathrm{~L} / \mathrm{min}$ of oxygen via nasal cannula showed a partial pressure of arterial oxygen $\left(\mathrm{PaO}_{2}\right)$ of $65 \mathrm{mmHg}$. He was placed on high-flow nasal cannula at $40 \mathrm{~L} / \mathrm{min}$ and $50 \%$ fraction of inspired oxygen with improvement in $\mathrm{PaO}_{2}$ to $105 \mathrm{mmHg}$. Laboratory workup was notable for hemoglobin $8.5 \mathrm{~g} / \mathrm{dL}$, reticulocyte count $349 \mathrm{k} / \mu \mathrm{L}, 55.2 \%$ hemoglobin $\mathrm{S}$, lactic acid $5.0 \mathrm{mmol} / \mathrm{L}$, lactate dehydrogenase $528 \mathrm{U} / \mathrm{L}$, total bilirubin $1.4 \mathrm{mg} / \mathrm{dL}$, creatinine $1.41 \mathrm{mg} / \mathrm{dL}$, brain natriuretic peptide $586 \mathrm{pg} / \mathrm{mL}$, and troponin $4.09 \mathrm{ng} / \mathrm{mL}$. Chest radiograph showed slight left greater than right suprahilar opacities (Figure 1(b)), and computed tomography angiogram did not demonstrate a pulmonary embolism. Echocardiogram revealed a severely enlarged $\mathrm{RV}$ with severely reduced systolic function and an ePASP of $132 \mathrm{mmHg}$ (Figure 2). There was concern for ACS. The patient received empiric vancomycin, meropenem, and azithromycin and underwent exchange transfusion of three units packed red blood cells with improvement in hemoglobin S to $26 \%$. Despite these therapies, he had worsening hypotension over the following twenty-four hours, including requiring up to three vasopressors (norepinephrine, vasopressin, and epinephrine). Cardiology was consulted and, given the unclear etiology of his decompensation, a RHC with a retained pulmonary artery catheter was rapidly performed and demonstrated severely decompensated precapillary $\mathrm{PH}$, acute RV failure, and cardiogenic shock (Table 1).

$\mathrm{He}$ was diuresed and started on dobutamine. Given his predominantly precapillary $\mathrm{PH}$ on RHC, he was also initiated on inhaled epoprostenol to allow for RV afterload reduction and avoid intubation (which was considered extremely high risk). He initially showed rapid improvement and was weaned from epinephrine and vasopressin in the following twelve hours. However, he failed to improve further despite effective diuresis, normal oxygenation, empiric antibiotics, and additional exchange transfusions. He continued to require high-dose dobutamine and inhaled epoprostenol for the following four days. Cardiac index, calculated by the indirect Fick method using a central venous catheter, remained 1.7-1.9 L/min $/ \mathrm{m}^{2}$, and attempts to wean inotropic support resulted in hypotension. After several days of inability to wean dobutamine, it became clear that he was in persistent $\mathrm{RV}$ failure. Alternative therapies were considered to decrease $\mathrm{RV}$ afterload and allow for downtitration of inotropic and inhaled vasodilator support.

Phosphodiesterase inhibitors were avoided due to evidence of increased adverse effects in patients with SCD [7]. Endothelin receptor antagonists were avoided because of their potential to cause anemia and fluid retention, especially given the patient's low hemoglobin, active hemolysis, and decompensated heart failure. Intravenous therapies were considered, although they are not available at our institution and transfer to a tertiary center was declined.

Given that the patient had responded well to inhaled epoprostenol, it was felt that an oral agent acting upon the prostanoid pathway was appropriate to trial. We reviewed the literature and found that rapid uptitration of selexipag had been safe in healthy subjects and patients with PH [10-13]. Ultimately, he was initiated on rapidly uptitrated doses of selexipag, reaching target dosing of $1600 \mu \mathrm{g}$ twice daily over fifteen days. During the rapid uptitration, the patient denied symptoms associated with prostacyclin intolerance. Two days after initiation of selexipag, cardiac index improved to greater than $2 \mathrm{~L} / \mathrm{min} / \mathrm{m}^{2}$, and right atrial pressure decreased to less than $10 \mathrm{mmHg}$; eight days after initiation, he was able to be weaned completely from dobutamine and epoprostenol. He was discharged on hospital day 21 and followed up in the cardiology clinic twice in the following year without further episodes of ACS or RV failure. Follow-up echocardiogram ten months after hospitalization on selexipag and macitentan showed improved RV size and function with ePASP $45 \mathrm{mmHg}$ (Figure 1(c)).

\section{Discussion}

The mainstay of therapy for ACS is adequate and immediate pain control, prevention of hypovolemia and hypoxemia, empiric antibiotics, and exchange transfusion to achieve hemoglobin $S<30 \%$. ACS can be caused by infection, pulmonary embolization, and asthma exacerbation, or the trigger can be unknown. However, in patients with a history of $\mathrm{PH}, \mathrm{ACS}$ may present with worsening RV failure. Acute RV failure from decompensated pulmonary arterial hypertension $(\mathrm{PAH})$ is treated with pulmonary vasodilators, inotropic agents, and preload optimization. However, in treating this patient, we learned that little evidence exists to guide management of ACS in SCD when precapillary PH and RV failure persists following the resolution of reversible triggers.

Use of pulmonary vasodilators in SCD-associated PH has been understudied in general, not just in ACS. A randomized controlled trial comparing bosentan to placebo in SCDassociated $\mathrm{PH}$ was terminated early due to underenrollment [14]. The walk-PHaSST trial was stopped early due to 


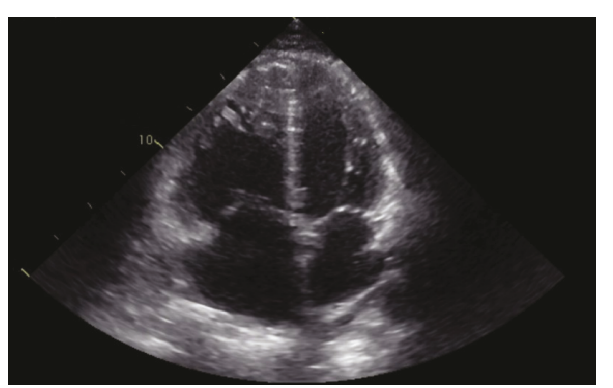

(a)

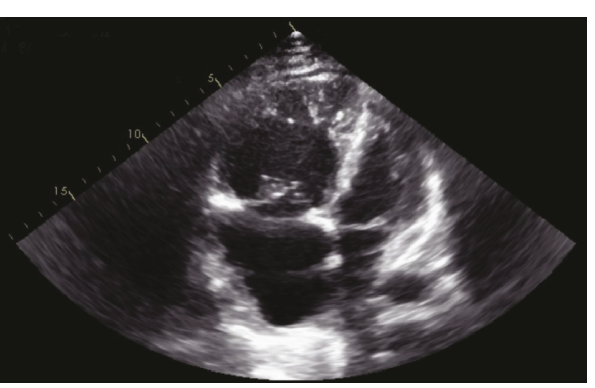

(b)

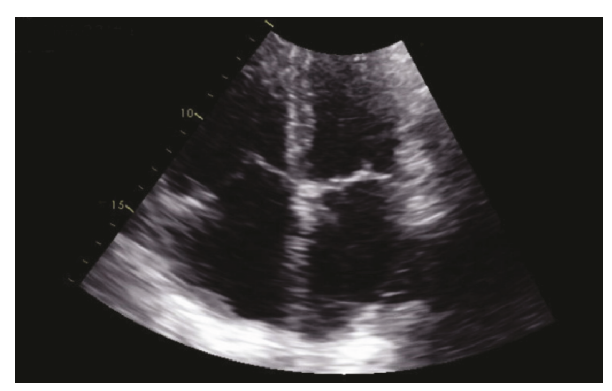

(c)

FIGURE 1: Apical four-chamber views and abbreviated echocardiogram reports from the baseline, acute chest syndrome (ACS), and follow-up. (a) Baseline echocardiogram. Twenty-two months prior to ACS. Left ventricular ejection fraction 55-60\%. Moderately enlarged right ventricular chamber with mildly reduced systolic function. Mild right atrial enlargement. Moderate tricuspid regurgitation. Pulmonary artery systolic pressure $60 \mathrm{mmHg}$ plus central venous pressure. Inferior vena cava small and collapses with inspiration. (b) Echocardiogram during ACS. Left ventricular ejection fraction 60-65\%. Severely enlarged right ventricular chamber with moderately reduced systolic function. Severe right atrial enlargement. Severe tricuspid regurgitation. Pulmonary artery systolic pressure $132 \mathrm{mmHg}$ plus central venous pressure. Inferior vena cava dilated. (c) Follow-up echocardiogram. Ten months after ACS. Left ventricular ejection fraction 55-60\%. Moderately enlarged right ventricular chamber with moderately reduced systolic function. Moderate right atrial enlargement. Moderate tricuspid regurgitation. Pulmonary artery systolic pressure $45 \mathrm{mmHg}$ plus central venous pressure. Inferior vena cava normal in caliber and collapses with inspiration.

TABLE 1: Hemodynamics on right heart catheterization nineteen months prior to hospitalization (baseline) in comparison to during acute chest syndrome (ACS).

\begin{tabular}{lcc}
\hline & Baseline & ACS \\
\hline Mean right atrial pressure & $5 \mathrm{mmHg}$ & $18 \mathrm{mmHg}$ \\
Right ventricular pressure & $40 / 3 \mathrm{mmHg}$ & $89 / 10 \mathrm{mmHg}$ \\
Pulmonary artery pressure (mean) & $42 / 16(25) \mathrm{mmHg}$ & $95 / 46(58) \mathrm{mmHg}$ \\
Pulmonary capillary wedge pressure & $6 \mathrm{mmHg}$ & $10 \mathrm{mmHg}$ \\
Pulmonary vascular resistance & $3.9 \mathrm{Wood} \mathrm{units}$ & $13.6 \mathrm{Wood} \mathrm{units}$ \\
Cardiac output by thermodilution & $4.83 \mathrm{~L} / \mathrm{min}$ & $3.53 \mathrm{~L} / \mathrm{min}$ \\
Cardiac index by thermodilution & $2.57 \mathrm{~L} / \mathrm{min} / \mathrm{m}^{2}$ & $1.86 \mathrm{~L} / \mathrm{min} / \mathrm{m}^{2}$ \\
Arterial oxygen saturation & $97 \%$ & $98 \%$ \\
Pulmonary artery oxygen saturation & $69 \%$ & $53 \%$ \\
Hemoglobin & $12.4 \mathrm{~g} / \mathrm{dL}$ & $10.6 \mathrm{~g} / \mathrm{dL}$ \\
\hline
\end{tabular}

increased pain crises in patients receiving sildenafil; furthermore, therapy with sildenafil did not improve hemodynamics or exercise capacity [7]. The American Thoracic Society recommends a trial of either a prostacyclin agonist or an endothelin receptor antagonist in patients with SCD and precapillary $\mathrm{PH}$ [2]. However, these recommendations apply to stable outpatients, and the efficacy of vasodilators in ACS is largely unknown.
Inhaled nitric oxide is the best-studied pulmonary vasodilator in treatment of vasoocclusive crises and ACS. In vasoocclusive pain crises, small trials have suggested that iNO is beneficial $[15,16]$, although this was not confirmed in a larger multicenter trial [17]. In ACS, several case reports have suggested that iNO is safe and effective [18, 19]. However, the only randomized placebo-controlled trial of iNO in ACS did not show statistically significant differences in 


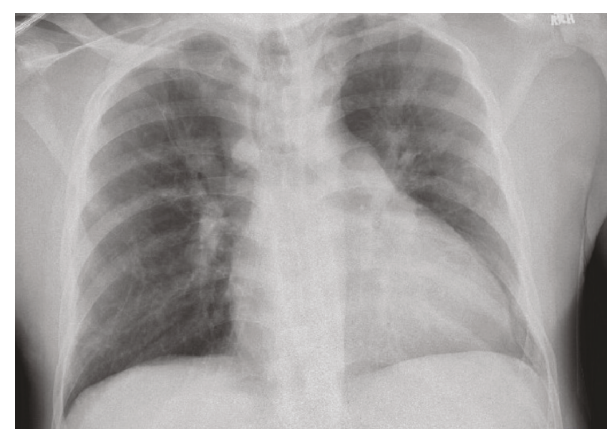

FIGURE 2: Chest radiograph from time of acute chest syndrome diagnosis.

mortality or need for endotracheal intubation. Notably, patients with hypotension were excluded from this trial [20]. It may be the case that pulmonary vasodilators are beneficial in subgroups of patients who experience RV failure and refractory hypotension as a predominant component of ACS. Other medications, such as epoprostenol or oral pulmonary vasodilators, have not been studied in ACS. Nonetheless, intravenous pulmonary vasodilators and/or iNO are standard of care in decompensated $\mathrm{PAH}$ [21].

In this case, we chose to initiate pulmonary vasodilators only when RV failure persisted after the acute ACS event; all other parameters (oxygenation, diuresis, and inotropy) had been optimized, and invasive hemodynamics confirmed severely decompensated precapillary $\mathrm{PH}$. We used inhaled epoprostenol and, later, selexipag for RV afterload reduction because of limited access to intravenous prostanoid therapies. It is difficult to determine if the clinical improvement seen in this patient was due to pulmonary vasodilator therapy or delayed resolution of ACS; however, hemodynamic improvement occurred only after vasodilator initiation. Improved afterload reduction with pulmonary vasodilators may have allowed for more successful downtitration of inotropic therapy. In our interpretation, this case demonstrates the potential utility of RV afterload reduction with pulmonary vasodilators in nontraditional clinical settings such as ACS. Certainly, definitive management conclusions cannot be drawn from a single case report. However, given what is known about the pathophysiology of ACS, SCDassociated $\mathrm{PH}$, and $\mathrm{RV}$ failure, pulmonary vasodilation should be studied further among patients in whom ACS is complicated by decompensated precapillary $\mathrm{PH}$ and cardiogenic shock.

\section{Conflicts of Interest}

The authors declare no conflicts of interest.

\section{Acknowledgments}

Publication is made possible in part by support from the UCSF Open Access Publishing Fund.

\section{References}

[1] G. H. H. Fonseca, R. Souza, V. M. C. Salemi, C. V. P. Jardim, and S. F. M. Gualandro, "Pulmonary hypertension diagnosed by right heart catheterisation in sickle cell disease," European Respiratory Journal, vol. 39, no. 1, pp. 112-118, 2012.

[2] E. S. Klings, R. F. Machado, R. J. Barst et al., "An official American Thoracic Society clinical practice guideline: diagnosis, risk stratification, and management of pulmonary hypertension of sickle cell disease," American Journal of Respiratory and Critical Care Medicine, vol. 189, no. 6, pp. 727-740, 2014.

[3] V. R. Gordeuk, O. L. Castro, and R. F. Machado, "Pathophysiology and treatment of pulmonary hypertension in sickle cell disease," Blood, vol. 127, no. 7, pp. 820-828, 2016.

[4] A. Mehari, M. T. Gladwin, X. Tian, R. F. Machado, and G. J. Kato, "Mortality in adults with sickle cell disease and pulmonary hypertension," JAMA, vol. 307 , no. 12 , pp. 1254-1256, 2012.

[5] A. Mehari, S. Alam, X. Tian et al., "Hemodynamic predictors of mortality in adults with sickle cell disease," American Journal of Respiratory and Critical Care Medicine, vol. 187, no. 8, pp. 840-847, 2013.

[6] R. Colombatti, N. Maschietto, E. Varotto et al., "Pulmonary hypertension in sickle cell disease children under 10 years of age," British Journal of Haematology, vol. 150, no. 5, pp. 601609, 2010.

[7] R. F. Machado, R. J. Barst, N. A. Yovetich et al., "Hospitalization for pain in patients with sickle cell disease treated with sildenafil for elevated TRV and low exercise capacity," Blood, vol. 118, no. 4, pp. 855-864, 2011.

[8] A. Mekontso Dessap, R. Leon, A. Habibi et al., "Pulmonary hypertension and cor pulmonale during severe acute chest syndrome in sickle cell disease," American Journal of Respiratory and Critical Care Medicine, vol. 177, no. 6, pp. 646-653, 2008.

[9] M. T. Gladwin and V. Sachdev, "Cardiovascular abnormalities in sickle cell disease," Journal of the American College of Cardiology, vol. 59, no. 13, pp. 1123-1133, 2012.

[10] S. Bruderer, N. Hurst, P. Kaufmann, and J. Dingemanse, "Multiple-dose up-titration study to evaluate the safety, tolerability, pharmacokinetics, and pharmacodynamics of selexipag, an orally available selective prostacyclin receptor agonist, in healthy subjects," Pharmacology, vol. 94, no. 3-4, pp. 148156, 2014.

[11] K. M. Thurber, B. M. Williams, R. E. Bates, and R. P. Frantz, "Transition of intravenous treprostinil to oral therapy in a patient with functional class IV chronic thromboembolic pulmonary hypertension," Pharmacotherapy, vol. 37, no. 8, pp. e76-e81, 2017.

[12] A. Furukawa, Y. Tamura, H. Iwahori et al., "Successful transition from treprostinil to selexipag in patient with severe pulmonary arterial hypertension," BMC Pulmonary Medicine, vol. 17, no. 1, p. 135, 2017.

[13] C. Miller, Transition from parenteral prostacyclin to selexipag in patients with pulmonary arterial hypertension, American Journal of Respiratory and Critical Care Medicine, Washington, DC, 2017.

[14] R. J. Barst, K. K. Mubarak, R. F. Machado et al., "Exercise capacity and haemodynamics in patients with sickle cell disease with pulmonary hypertension treated with bosentan: results of the ASSET studies," British Journal of Haematology, vol. 149 , no. 3 , pp. $426-435,2010$. 
[15] D. L. Weiner, P. L. Hibberd, P. Betit, A. B. Cooper, C. A. Botelho, and C. Brugnara, "Preliminary assessment of inhaled nitric oxide for acute vaso-occlusive crisis in pediatric patients with sickle cell disease," JAMA, vol. 289, no. 9, pp. 1136-1142, 2003.

[16] C. A. Head, P. Swerdlow, W. A. McDade et al., "Beneficial effects of nitric oxide breathing in adult patients with sickle cell crisis," American Journal of Hematology, vol. 85, no. 10, pp. 800-802, 2010.

[17] M. T. Gladwin, G. J. Kato, D. Weiner et al., "Nitric oxide for inhalation in the acute treatment of sickle cell pain crisis: a randomized controlled trial," JAMA, vol. 305 , no. 9, pp. $893-$ 902, 2011.

[18] A. M. Atz and D. L. Wessel, "Inhaled nitric oxide in sickle cell disease with acute chest syndrome," Anesthesiology, vol. 87, no. 4, pp. 988-990, 1997.

[19] S. Choudhuri, B. Ray, and D. Mohanty, "Relief of acute chest syndrome of sickle cell anaemia by nitric oxide inhalation - a report of 2 cases," Medical Reports \& Case Studies, vol. 3, no. 2, 2018.

[20] B. Maitre, M. Djibre, S. Katsahian et al., "Inhaled nitric oxide for acute chest syndrome in adult sickle cell patients: a randomized controlled study," Intensive Care Medicine, vol. 41, no. 12, pp. 2121-2129, 2015.

[21] V.-P. Harjola, A. Mebazaa, J. Čelutkienė et al., "Contemporary management of acute right ventricular failure: a statement from the Heart Failure Association and the Working Group on Pulmonary Circulation and Right Ventricular Function of the European Society of Cardiology," European Journal of Heart Failure, vol. 18, no. 3, pp. 226-241, 2016. 


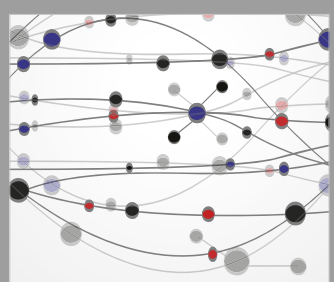

The Scientific World Journal
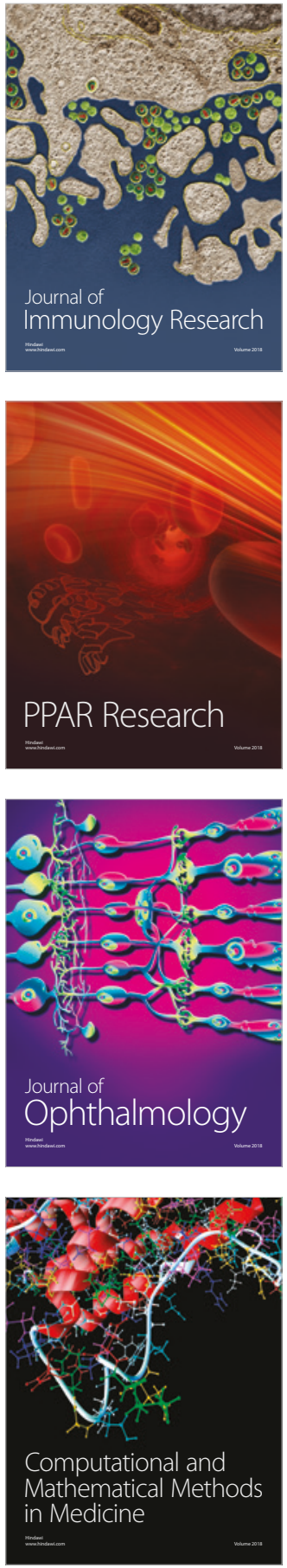

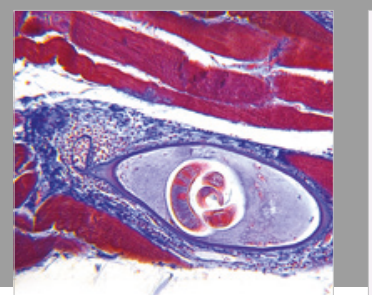

Gastroenterology Research and Practice

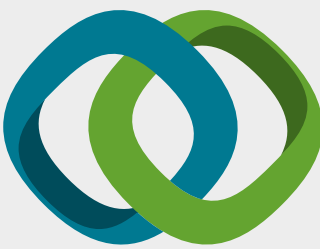

\section{Hindawi}

Submit your manuscripts at

www.hindawi.com
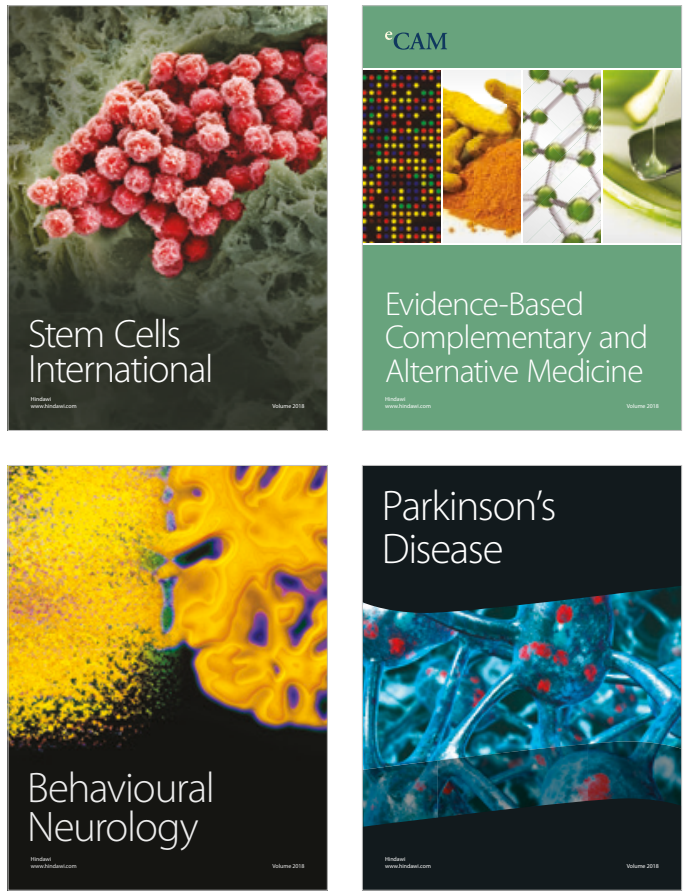

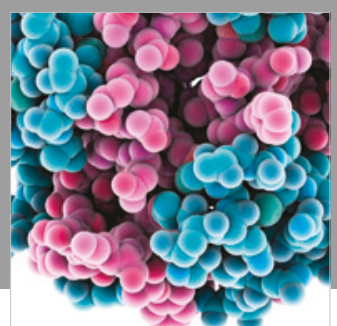

ournal of

Diabetes Research

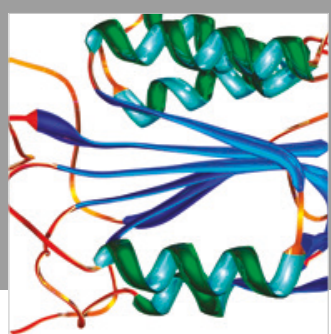

Disease Markers
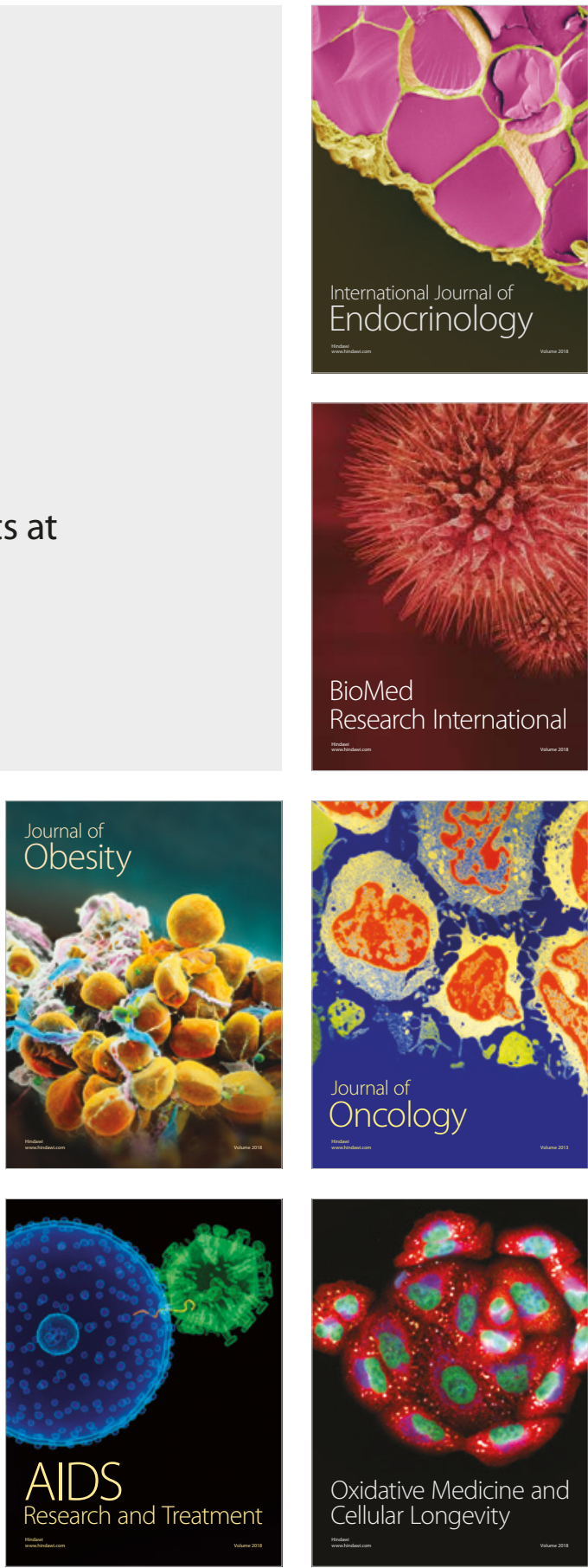